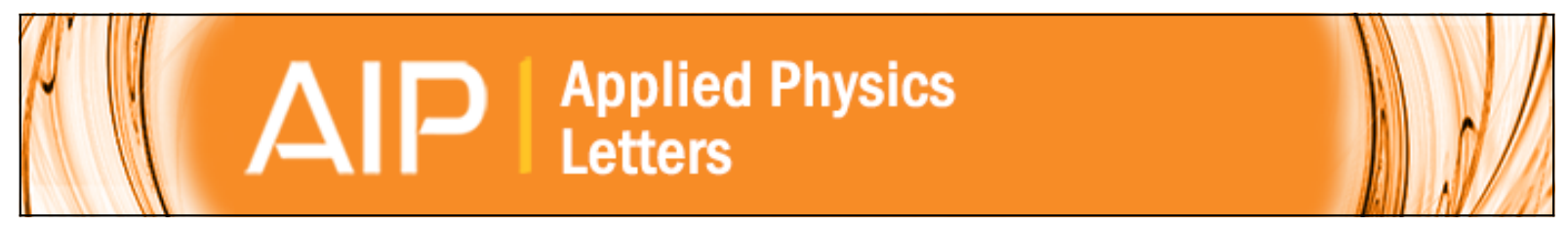

Photoluminescence of near-lattice-matched Ga N Al In N quantum wells grown on freestanding GaN and on sapphire substrates

L. T. Tan, R. W. Martin, K. P. O'Donnell, I. M. Watson, Z. H. Wu, and F. A. Ponce

Citation: Applied Physics Letters 92, 031907 (2008); doi: 10.1063/1.2837630

View online: http://dx.doi.org/10.1063/1.2837630

View Table of Contents: http://scitation.aip.org/content/aip/journal/apl/92/3?ver=pdfcov

Published by the AIP Publishing 


\title{
Photoluminescence of near-lattice-matched GaN/AllnN quantum wells grown on free-standing GaN and on sapphire substrates
}

\author{
L. T. Tan, R. W. Martin, ${ }^{\text {a) }}$ and K. P. O'Donnell \\ Department of Physics, SUPA, University of Strathclyde, Glasgow G4 ONG, United Kingdom \\ I. M. Watson \\ Institute of Photonics, SUPA, University of Strathclyde, Glasgow G4 ONW, United Kingdom
}

Z. H. Wu and F. A. Ponce

Department of Physics and Astronomy, Arizona State University, Tempe, Arizona 85287-1504, USA

(Received 6 November 2007; accepted 4 January 2008; published online 25 January 2008)

\begin{abstract}
Near-lattice-matched $\mathrm{GaN} / \mathrm{Al}_{1-x} \mathrm{In}_{x} \mathrm{~N}$ single quantum wells, grown using both free-standing $\mathrm{GaN}$ and conventional GaN-on-sapphire substrates, are studied by photoluminescence (PL) and PL excitation spectroscopies. PL spectra distinguish luminescence originating in the wells, barriers, and underlying GaN buffer layers. The spectra also reveal significant differences between structures grown simultaneously on the different substrates. The quantum well transition energy decreases as the well width increases due to the intense in-built electric fields, estimated to be $3.0 \pm 0.5 \mathrm{MeV} / \mathrm{cm}$, that persist in strain free $\mathrm{GaN} / \mathrm{Al}_{1-x} \mathrm{In}_{x} \mathrm{~N}$. Screening of these fields is studied using the excitation power dependence of the PL. (C) 2008 American Institute of Physics. [DOI: 10.1063/1.2837630]
\end{abstract}

The band gaps of the ternary alloy $\mathrm{Al}_{1-x} \mathrm{In}_{x} \mathrm{~N}$ cover an extremely large range of energy $(0.7-6.2 \mathrm{eV})$, opening up many significant III-nitride optoelectronic applications. Most importantly, $\mathrm{Al}_{1-x} \mathrm{In}_{x} \mathrm{~N}$ can be lattice matched to $\mathrm{GaN}$ with an InN fraction of approximately $17 \% .{ }^{1-4}$ With freestanding GaN (FS-GaN) substrates now commercially available, deployment of lattice-matched $\mathrm{Al}_{1-x} \mathrm{In}_{x} \mathrm{~N}$ can reduce defect densities in strain free GaN-based devices, such as laser diodes and transistors. Reference 5 demonstrates the strain-free state and sharp excitonic transitions in the topmost $\mathrm{GaN}$ layers of lattice-matched GaN-AlInN-GaN trilayer structures grown on FS-GaN. In addition, lattice-matched $\mathrm{GaN} / \mathrm{Al}_{1-x} \mathrm{In}_{x} \mathrm{~N}$ is an alternative to $\mathrm{GaN} / \mathrm{Al}_{1-y} \mathrm{Ga}_{y} \mathrm{~N}$ for mid-infrared intersubband devices and can be used as cladding layers for optical waveguides due to its relatively high refractive index contrast with GaN. ${ }^{6}$ This has allowed the development of lattice-matched III-N dielectric Bragg mirrors ${ }^{2,7}$ and insertion layers for in situ growth monitoring by reflectometry. ${ }^{3}$ Nevertheless, some properties of $\mathrm{Al}_{1-x} \mathrm{In}_{x} \mathrm{~N}$ remain unclear owing to the challenge of finding growth conditions allowing efficient co-incorporation of aluminum and indium into single-phase layers of high crystal quality. At the same time, differences in growth on FS-GaN and $\mathrm{GaN}$-on-sapphire substrates have not been explored.

In this letter, we describe a study of the optical properties of near-lattice-matched $\mathrm{GaN} / \mathrm{Al}_{1-x} \mathrm{In}_{x} \mathrm{~N}$ single quantum wells (SQWs) grown at the same time on the (0001) sapphire and FS-GaN substrates, as a function of GaN well width. Photoluminescence (PL) and PL excitation (PLE) spectra are used to characterize the wells and provide information on the optical properties of the near-lattice-matched $\mathrm{Al}_{1-x} \mathrm{In}_{x} \mathrm{~N}$ barriers.

$\mathrm{GaN} / \mathrm{Al}_{1-x} \mathrm{In}_{x} \mathrm{~N}$ SQW samples were grown by metalorganic chemical vapor deposition in an Aixtron 200-series reactor. SQWs of nominal thicknesses of 1.5, 3, and $4 \mathrm{~nm}$

\footnotetext{
${ }^{a)}$ Electronic mail: r.w.martin@strath.ac.uk.
}

were grown on $1.5 \mu \mathrm{m} \mathrm{GaN}$ buffer layers on $c$-plane sapphire substrates. These have $\mathrm{Al}_{1-x} \mathrm{In}_{x} \mathrm{~N}$ lower barriers and caps both of $10 \mathrm{~nm}$ thickness and nominal $\mathrm{InN}$ fractions of 0.17. Similar GaN SQWs of nominal thicknesses of 2.5 and $4 \mathrm{~nm}$ were grown simultaneously on FS-GaN substrates and GaN-on-sapphire templates. In these samples, the thickness of the $\mathrm{Al}_{1-x} \mathrm{In}_{x} \mathrm{~N}$ barriers below the SQWs is increased to $100 \mathrm{~nm}$, with $10 \mathrm{~nm} \mathrm{Al}_{1-x} \mathrm{In}_{x} \mathrm{~N}$ caps. FS-GaN substrates had polished backsides, while the templates had nonpolished backsides. No intentional doping was used in any layer, and the GaN SQW material was grown at the same temperature as the $\mathrm{Al}_{1-x} \mathrm{In}_{x} \mathrm{~N}$ (a setpoint of either $815^{\circ} \mathrm{C}$ or $820^{\circ} \mathrm{C}$ ), at which its growth rate was under kinetic control. SQW thicknesses were determined by the growth time, assuming a growth rate of $54 \mathrm{~nm} / \mathrm{h}$, measured in a separate calibration run. Figure 1 shows a transmission electron microscopy (TEM) image of the sample with a nominal well width of $4 \mathrm{~nm}$, grown on a sapphire substrate, confirming an actual SQW thickness close to the target value and the coherent nature of the interfaces.

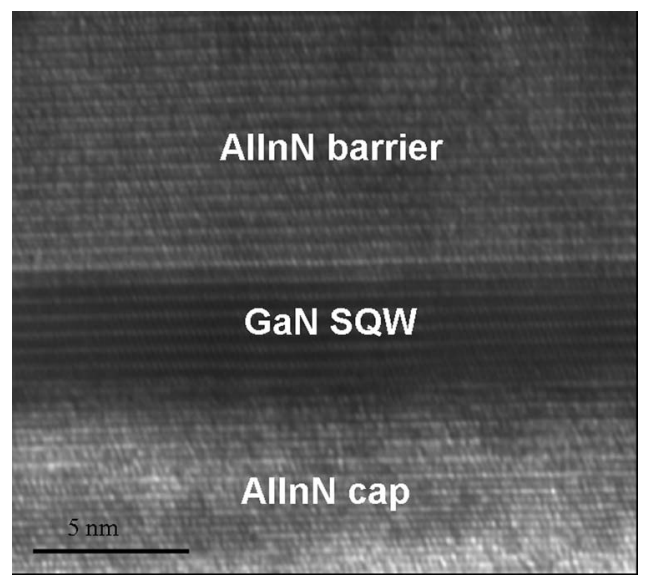

FIG. 1. TEM image of near-lattice-matched $4 \mathrm{~nm}$ GaN/ $\mathrm{Al}_{1-x} \mathrm{In}_{x} \mathrm{~N} S \mathrm{SQ}$ grown on a sapphire substrate. 


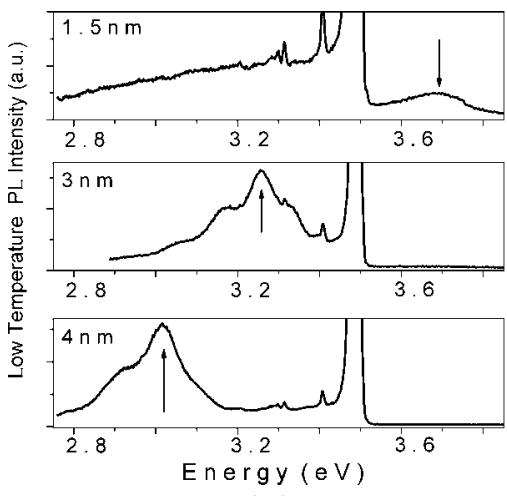

(a)

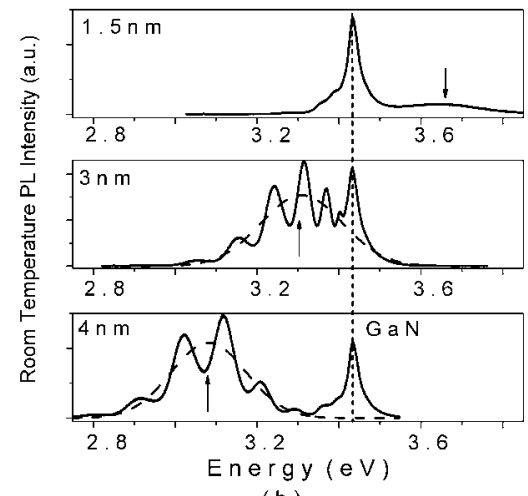

(b)
FIG. 2. PL spectra of $\mathrm{GaN} / \mathrm{Al}_{1-x} \mathrm{In}_{x} \mathrm{~N}$ SQWs with thin $10 \mathrm{~nm}$ lower barriers on sapphire substrates using (a) $280 \mathrm{~nm} \mathrm{Xe} \mathrm{lamp} \mathrm{at} \approx 17 \mathrm{~K}$ and (b) $244 \mathrm{~nm}$ laser excitation at RT. The QW emission peaks are indicated by the arrows.
PL was excited by monochromated emission from a $1000 \mathrm{~W}$ xenon $(\mathrm{Xe})$ lamp or by the $244 \mathrm{~nm}$ line of an $\mathrm{Ar}^{+}$ laser. PLE spectra were obtained by scanning the source monochromator and corrected for the lamp output and throughput of the monochromator. The incident lamp power on the sample averages $0.3 \mathrm{~mW}$ on a surface area of $\sim 2$ $\times 5 \mathrm{~mm}^{2}$. The laser power varied from 0.03 to $1.2 \mathrm{~mW}$ in a $10 \mu \mathrm{m}$ spot size. Samples were maintained at $\sim 17 \mathrm{~K}$ in a closed-cycle helium cryostat for the lamp excitation and at room temperature (RT) for the laser excitation.

Figure 2 compares PL spectra of GaN SQWs with (thin) $10 \mathrm{~nm}$ lower $\mathrm{Al}_{1-x} \mathrm{In}_{x} \mathrm{~N}$ barriers on sapphire substrates, produced by $280 \mathrm{~nm}$ Xe lamp and $244 \mathrm{~nm}$ laser excitation. The QW peak energy decreases rapidly from 3.65 to $3.0 \mathrm{eV}$ as the well width increases from 1.5 to $4 \mathrm{~nm}$, moving well below the bulk $\mathrm{GaN}$ band gap of $3.5 \mathrm{eV}$. Similar behavior is seen in the samples on FS-GaN substrates. This shift is due to a quantum confined Stark effect resulting from intense in-built electric fields. For near-lattice-matched material, the piezo-component of this field approaches zero but intense polarization (pyroelectric) fields remain. Interference fringes are more prominent in the laser excited spectra, probably due to better local flatness of the sample in the much smaller measurement area. The lower relative intensity in the laser spectra of the $\mathrm{GaN}$ peak at $\sim 3.45 \mathrm{eV}$ is due to the difference in the temperature and excitation power intensity.

Figure 3 plots the SQW peak energy as a function of nominal well width for samples grown on sapphire and FS-GaN substrates, including a sample on sapphire with a thicker lower barrier (see Fig. 4). A linear variation of the

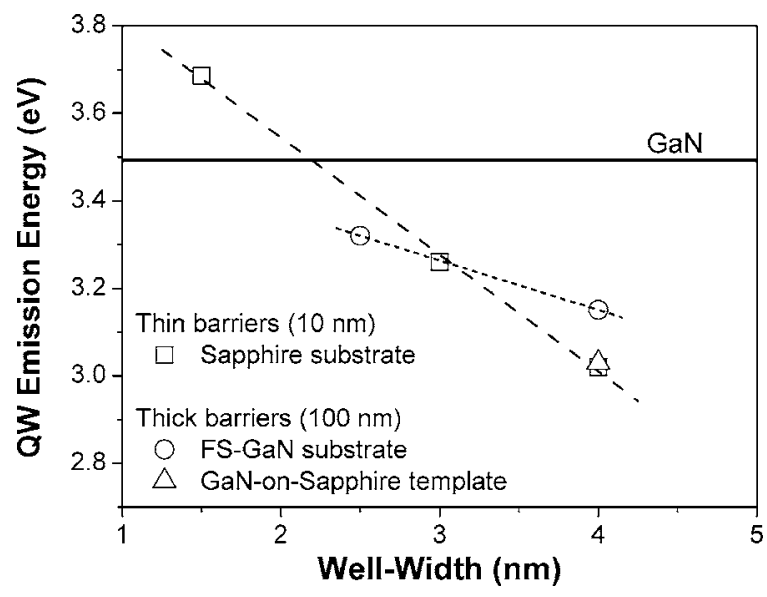

FIG. 3. QW emission energy as a function of well width for samples grown on sapphire and FS-GaN substrates The dashed lines are guides for the eye indicating different gradients for the two types of substrates. peak PL energy with well width is observed for the samples on sapphire, similar to that shown by $\mathrm{GaN} / \mathrm{Al}_{1-y} \mathrm{Ga}_{y} \mathrm{~N}$ heterostructures. ${ }^{8,9}$ The two data points for FS-GaN samples suggest a slower redshift of the SQW peak with increasing well width. The SQW emission peak for a well width of $1.5 \mathrm{~nm}$ exceeds that of the $\mathrm{GaN}$ band gap, due to the effects of quantum confinement, but rapidly falls below this value as the width increases. The electric field is estimated to be $3.0 \pm 0.5 \mathrm{MV} / \mathrm{cm}$, using single particle calculations of confined energy levels. An earlier study of lattice-matched $\mathrm{GaN} / \mathrm{Al}_{1-x} \mathrm{In}_{x} \mathrm{~N}$ quantum wells on sapphire reported a redshift of similar gradient. ${ }^{6}$ However, the reported emission energies for a given well width are offset from those in the present work, probably due to systematic differences in the well widths or different residual strains resulting from the $\mathrm{Al}_{1-x} \mathrm{In}_{x} \mathrm{~N}$ composition (as discussed below).

A direct comparison of PL measured at room temperature from $4 \mathrm{~nm} \mathrm{SQW} \mathrm{samples} \mathrm{with} \mathrm{thick} \mathrm{lower} \mathrm{Al}_{1-x} \mathrm{In}_{x} \mathrm{~N}$ barriers, grown simultaneously on GaN-on-sapphire and FSGaN substrates, is made in Fig. 4. Emission from the SQW has similar intensity in the two structures. Emission from the barrier itself is now observed near $3.86 \mathrm{eV}(3.71 \mathrm{eV})$ for sapphire (FS-GaN) substrates, in addition to the PL peaks from the SQW and underlying GaN. Interference fringes are not present for FS-GaN substrates and the peaks are shifted compared to the equivalent structure on GaN-on-sapphire: the SQW transition energy blueshifts whilst the barrier emission redshifts. These spectral shifts are attributable to small substrate surface temperature variations resulting from different characteristics of the two substrates. The FS-GaN substrates evidently had a lower surface temperature than the GaN-on-sapphire templates, resulting in a lower SQW

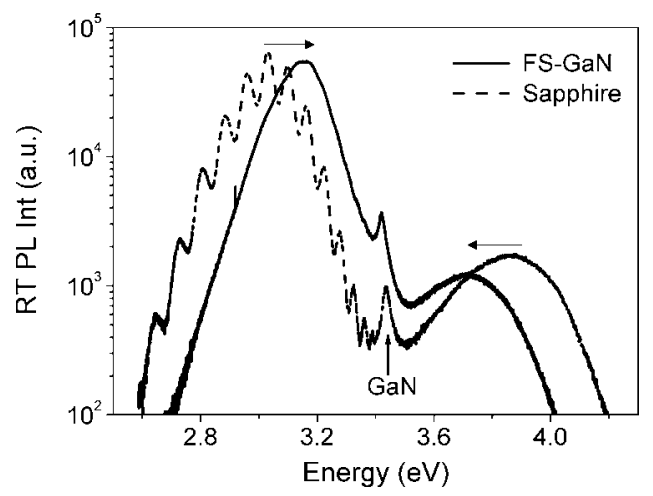

FIG. 4. RT PL spectra of the $4 \mathrm{~nm} \mathrm{GaN} / \mathrm{Al}_{1-x} \mathrm{In}_{x} \mathrm{~N}$ SQWs grown simultaneously on GaN-on-sapphire templates and FS-GaN substrates excited by the laser. The thickness of the lower $\mathrm{Al}_{1-x} \ln _{x} \mathrm{~N}$ barriers is $100 \mathrm{~nm}$. 

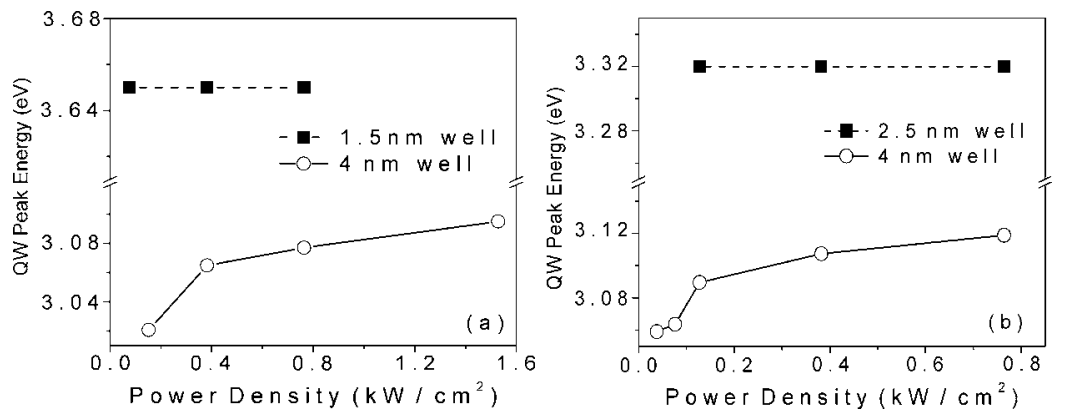

FIG. 5. Emission energies as a function of excitation power density for $\mathrm{GaN} / \mathrm{Al}_{1-x} \mathrm{In}_{x} \mathrm{~N}$ SQWs grown on (a) sapphire and (b) FS-GaN substrates using laser excitation at room temperature. growth rate, and higher $\mathrm{InN}$ incorporation in the barrier. The net temperature difference arose from an interplay of the different thermal conductivities (approximately three times higher for FS-GaN than sapphire), backside finishes, thicknesses, and planarity of the different substrates. The GaN emission peak $(\sim 3.42 \mathrm{eV})$ is the same in both samples and very close to the value for strain-free GaN described in Ref. 10. Wavelength dispersive $\mathrm{X}$-ray analysis shows all the SQW samples on FS-GaN substrates to be closer to lattice match than the corresponding structures grown on sapphire. The InN fractions measured for these "thick lower barrier" samples are close to 0.18 and $0.14-0.15$ ( \pm 0.01$)$ for structures grown on FS-GaN and sapphire, respectively. Comparison of the $\mathrm{Al}_{1-x} \operatorname{In}_{x} \mathrm{~N}$ PL peak energy in Fig. 4 with data from $\mathrm{Al}_{1-x} \mathrm{In}_{x} \mathrm{~N}$ epilayers ${ }^{4}$ gives good agreement with this estimated difference in InN fraction. Reducing the InN composition in the barriers below the lattice-match point results in a piezoelectric field that reinforces the spontaneous polarization field. The increased field for the more highly strained samples grown on sapphire, compared to those on FS-GaN, is illustrated by the steeper gradient in Fig. 3.

There is a strong dependence of the SQW transition energy on the excitation intensity for some SQW widths, but not for others, as shown in Fig. 5. Similar behavior is seen for the $4 \mathrm{~nm}$ wells grown on both sapphire and FS-GaN substrates. However, there is no change in the SQW transition energy for thin SQW $(<2-3 \mathrm{~nm})$ as the power density varies from 0.4 to $15 \mathrm{~W} / \mathrm{mm}^{2}$. The screening of the internal electric field by photo-induced free carriers has a greater effect in the wider wells. Similar behavior has been reported in $\mathrm{InGaN} / \mathrm{GaN}$ MQWs. ${ }^{11}$

Selectively excited PL, and associated emission-peak PLE spectra, were measured at $\sim 17 \mathrm{~K}$ on the 3 and $4 \mathrm{~nm}$ SQW samples grown with thin barriers on sapphire substrates. As the excitation wavelength increases from 230 to $340 \mathrm{~nm}$, no change in the PL peak position of the SQW is observed but the peak intensity first increases and then decreases. The position of the $\mathrm{Al}_{1-x} \operatorname{In}_{x} \mathrm{~N}$ band edge was confirmed by PLE spectroscopy to be near $275 \mathrm{~nm}$ $(\sim 4.5 \mathrm{eV})$.
In summary, photoluminescence of near-lattice-matched $\mathrm{GaN} / \mathrm{Al}_{1-x} \mathrm{In}_{x} \mathrm{~N}$ single quantum well structures, on sapphire and FS-GaN substrates, have been studied as a function of $\mathrm{GaN}$ well width. The results are interpreted in terms of differences in the well widths and $\mathrm{Al}_{1-x} \mathrm{In}_{x} \mathrm{~N}$ barrier composition between samples grown simultaneously on different substrates. The SQW luminescence peak energy decreases as the well width increases, mainly due to the intense spontaneous polarization fields persisting even in the absence of strain, and its dependence on excitation power reveals the effects of carrier screening.

L.T.T. gratefully acknowledges support from the ORS award scheme and the University of Strathclyde. Sample growth was supported by the EPSRC Platform (GR/S10636) grant. We thank D. Wolverson (University of Bath) for the loan of laser equipment for this work. Work at Arizona State University was supported by a grant from Nichia Corporation.

${ }^{1}$ J.-F. Carlin, C. Zellweger, J. Dorsaz, S. Nicolay, G. Christmann, E. Feltin, R. Butté, and N. Grandjean, Phys. Status Solidi B 242, 2326 (2005).

${ }^{2}$ K. Lorenz, N. Franco, E. Alves, I. M. Watson, R. W. Martin, and K. P. O’Donnell, Phys. Rev. Lett. 97, 085501 (2006).

${ }^{3}$ I. M. Watson, C. Liu, E. Gu, M. D. Dawson, P. R. Edwards, and R. W. Martin, Appl. Phys. Lett. 87, 151901 (2005).

${ }^{4}$ K. Wang, R. W. Martin, D. Amabile, P. R. Edwards, S. Hernandez, E. Nogales, K. P. O'Donnell, K. Lorenz, E. Alves, V. Matias, A. Vantomme, D. Wolverson, and I. M. Watson (unpublished).

${ }^{5}$ K. Bejtka, R. W. Martin, I. M. Watson, S. Ndiaye, and M. Leroux, Appl. Phys. Lett. 89, 191912 (2006).

${ }^{6}$ S. Nicolay, J.-F. Carlin, E. Feltin, R. Butté, M. Mosca, N. Grandjean, M. Ilegems, M. Tchernycheva, L. Nevou, and F. H. Julien, Appl. Phys. Lett. 87, 111106 (2005).

${ }^{7}$ J.-F. Carlin and M. Ilegems, Appl. Phys. Lett. 83, 668 (2003).

${ }^{8}$ N. Grandjean, B. Damilano, S. Dalmasso, M. Leroux, M. Laügt, and J. Massies, Phys. Status Solidi A 176, 219 (1999).

${ }^{9}$ M. D. Craven, P. Waltereit, J. S. Speck, and S. P. DenBaars, Appl. Phys. Lett. 84, 496 (2004).

${ }^{10}$ S. J. Chua, S. Tripathy, P. Chen, E. Takasuka, and M. Ueno, Physica E (Amsterdam) 25, 356 (2005).

${ }^{11}$ K. Kazlauskas, G. Tamulaitis, J. Mickevicius, E. Kuokstis, A. Zukauskas, Y. C. Cheng, H. C. Wang, C. F. Huang, and C. C. Yang, J. Appl. Phys. 97, 013525 (2005). 